\title{
Instituições e interesse público: os processos de comunicação pública como estratégia instituinte
}

Institutions and public interest: public communication processes as instituting strategy

Instituciones e interés público: los procesos de comunicación públicos como estrategia instituyente

\section{Fiorenza Zandonade Carnielli}

- Doutoranda e mestre em Comunicação e Informação pela Universidade Federal do Rio Grande do Sul (UFRGS)

- Membro do Grupo de Pesquisa em Comunicação Pública e Política (Nucop) da UFRGS

- Especialista em Gestão Estratégica da Comunicação pela Pontifícia Universidade Católica de Minas Gerais (PUC-Minas) e em Marketing, Branding e Comunicação pela Universidade Regional Integrada do Alto Uruguai e das Missões (URI) - campus de Frederico Westphalen

- Graduada em Jornalismo e Relações Públicas pela Universidade Federal de Minas Gerais (UFMG)

- Professora do curso de Relações Públicas na Universidade de Caxias do Sul (UCS)

- E-mail: fiorenzazc@gmail.com 


\section{Resumo}

Este artigo reflete sobre os processos de comunicação pública proporcionados a partir das instituições, apresentando uma proposta de abordagem da comunicação centrada nas perspectivas normativa, fática e estratégica. Para isso articula os conceitos de instituição, interesse público, comunicação pública, comunicação organizacional e estratégia, marcando a comunicação como estratégia instituinte. As três perspectivas mostram-se válidas para olhar para as instituições e perceber como elas articulam questões de interesse público e, portanto, são sujeitos da comunicação pública.

\section{PALAVRAS-CHAVE: COMUNICAÇÃO PÚBLICA •INSTITUIÇÃO •NORMATIVIDADE・FACTICIDADE・ESTRATÉGIA.}

\section{Abstract}

This article considers the processes of public communication provided by the institutions, presenting a proposal for addressing the communication centered on the normative, factual and strategic perspectives. Therefore, it develops the concepts of institution, public interest, public communication, organizational communication and strategy, emphasizing communication as an instituting strategy. The three perspectives are valid to look at institutions and understand how they articulate matters of public interest and are, therefore, subjects of public communication.

\section{KEYWORDS: PUBLIC COMMUNICATION・INSTITUTION •STANDARDIZATION・FACTICITY・STRATEGY.}

\section{Resumen}

En este artículo se reflexiona sobre los procesos de comunicación pública proporcionados por las instituciones, la presentación de una propuesta de abordaje de la comunicación centrada en las perspectivas normativa, fáctica y estratégica. Para eso, articula los conceptos de institución, interés público, comunicación pública, comunicación organizacional y estrategia, marcando la comunicación como estrategia instituyente. Las tres perspectivas se muestran válidas para mirar a las instituciones y ver cómo ellas articulan los temas de interés público y, por lo tanto, son sujetos de la comunicación pública. 
ste artigo propõe uma reflexão sobre os processos de comunicação pública proporcionados a partir das instituições, apresentando uma possibilidade de abordagem institucional centrada nas perspectivas normativa, fática e estratégica. ${ }^{1}$ A partir do marco teórico da comunicação pública, assume-se o pressuposto de que ela atua como qualificadora das democracias ao colocar em circulação temas de interesse público que acionam as pessoas.

Portanto, a conceituação da comunicação pública trabalhada não é identificada com a fala da coisa pública ou governamental, mas, antes, do interesse público. Sua abordagem passa pelo sistema político, tomando a democracia como sua condição, e por uma base teórica que articula conceitos de espaço público, esfera pública, além do tensionamento entre interesses públicos e privados. Considera-se que a comunicação pública promotora do debate público se dá pela circulação de temas de interesse na esfera pública, inclusive midiática, incitada por manifestações sociais, pela sociedade organizada, por seus cidadãos e também pelo Estado e por suas instituições (Weber, 2007, 2009, 2011).

Para o entendimento da instituição, é fundamental o acento em seu caráter permanentemente instituinte, 0 que significa não se limitar aos aspectos funcionais a ela associados, mas, sobretudo, atentar para os processos de interação comunicacional identificados com a própria gênese institucional. Portanto, a compreensão da comunicação faz referência ao paradigma relacional, que aborda as interações comunicativas (França, 1998) travadas pelos sujeitos individuais e coletivos na afirmação dos sentidos que dizem de si e do mundo.

Castoriadis defende que as relações sociais são instituídas porque "foram estabelecidas como maneiras de fazer universais, simbolizadas e sancionadas" (Castoriadis, 1982, p. 151). Isso implica uma abordagem de um sujeito ativo que trabalha sobre si mesmo, "é o sujeito efetivo e totalmente penetrado pelo mundo e pelos outros" (Castoriadis, 1982, p.128). Reconhecer essa proposição demanda entender a instituição como sujeito coletivo em ação e atentar para os sentidos apresentados e representados na interação dos seus atores. "A vida institucional de uma sociedade não se sustenta, não se preserva e não se transforma senão mediada pelas diferentes práticas e processos comunicativos empreendidos por sua coletividade" (França; Corrêa, 2012, p. 11). Em outras palavras, ao olhar uma instituição, a busca é por perceber o que a institui, o que se dá, necessariamente, por meio do processo comunicacional.

Usualmente, a atenção à instituição convoca o olhar para as questões formais, as regras postas em funcionamento, aquilo que normatiza e institucionaliza formalmente ou legalmente. Como indica Castoriadis (1982), o enfoque não está apenas no âmbito racional e funcional das instituições, mas também no simbólico. 0 olhar comunicacional está "no processo de gênese de sentido, e não nos sentidos já sancionados e longamente estabelecidos" (Braga, 2010, p. 49). Ou seja, é preciso ver as regras antes de estarem postas, como processo e estratégia, como prática social e interacional.

Ao abordar a institucionalização como processo fundamental para a construção social da realidade, Berger e Luckmann (1998) destacam a exigência da legitimação para o mundo institucional, pois é necessário interpretar o significado das instituições em várias fórmulas legitimadoras, capazes de contar a mesma história e transformar a memória biográfica de uma geração em legitimação para a próxima geração.

Portanto, a instituição é percebida enquanto encontro de sujeitos, espaço e prática de organização de sentidos do mundo e da atuação desses sujeitos nele. Assim, toma-se a instituição como espaço em que, incitados pelo encontro com o

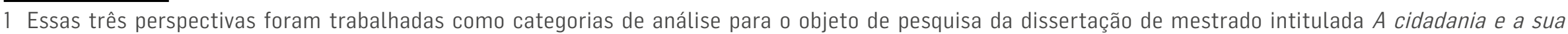

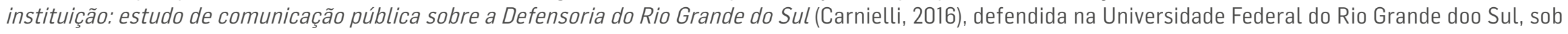
orientação de Maria Helena Weber. 
outro, os sujeitos oferecem e reconhecem significados. Esses significados, (re)estabelecem o lugar no mundo desses sujeitos e da própria instituição. Ou seja, é o agir comunicativo, a produção de sentidos, que institui a própria instituição em uma atividade permanente e fundadora.

A visão para a instituição a partir da comunicação pública pretendida neste artigo significa olhar para as instituições e buscar perceber como elas articulam sentidos públicos, questões de interesse público e, portanto, são sujeitos da comunicação pública. A partir desse propósito, o texto está organizado a seguir em três itens. 0 primeiro deles é dedicado à conceituação da comunicação pública, com destaque para a articulação necessária entre os aspectos normativos e fáticos, de forma a não conduzir uma análise puramente racional, distante das práticas concretas, e sem abrir mão da fundamental orientação ética. A seguir, aborda-se o caráter estratégico associado à comunicação pública e sua aproximação com a comunicação organizacional, com uma noção marcadamente relacional da estratégia. É com base no entendimento da comunicação pública sustentado nesses itens que, por fim, se apresenta uma proposta de abordagem da instituição a partir de três perspectivas: normativa, fática e estratégica.

\section{COMUNICAÇÃO PÚBLICA: ENTRE NORMA E FACTICIDADE}

Trabalhar a partir da perspectiva da comunicação pública significa, primeiro, fazer valer o papel central da comunicação para a compreensão da sociedade, entendendo que todo sentido social é forjado por meio de processos de interação comunicacional. Implica, igualmente, assumir que a comunicação pública traduz a democracia no sentido de que operacionaliza critérios democráticos fundantes como acessibilidade e discutibilidade, a partir dos quais são processadas as exigências de legitimidade do exercício do poder. Nesse sentido, como defende Esteves (2011), a comunicação pública é afirmada como medium por excelência de cidadania.

Para a definição de comunicação pública retoma-se o entendimento do que seja o público. 0 domínio público é plural por definição, o que significa que implica relação e reconhecimento permanente da alteridade. É resultado do exercício da possibilidade de verificar identidade apesar das diferenças de perspectivas representadas nesse espaço. Para definir o termo público, Arendt (2014) chama atenção para dois aspectos, o primeiro deles que público significa aquilo que é ouvido e visto por todos, destacando que o senso de realidade depende da aparência e, portanto, de um espaço de visibilidade compartilhado. "A presença de outros que veem o que vemos e ouvem o que ouvimos garante-nos a realidade do mundo e de nós mesmos" (Arendt, 2014, p. 62).

Como segundo aspecto, em íntima correlação com o primeiro, a autora aponta que público significa o espaço entre que separa e relaciona ao mesmo tempo. "O domínio público, enquanto mundo comum, reúne-nos na companhia uns dos outros e, contudo, evita que caiamos uns sobre os outros, por assim dizer" (Arendt, 2014, p. 65). Para ela, portanto, a experiência da alteridade, essencial para a percepção da realidade do mundo, dá-se no e é constitutiva do espaço público.

Como decorrência do reconhecimento de alteridades, o espaço público será ocupado por aquilo que é relevante por interessar e receber a atenção do público. A constituição do interesse público reside, como chama atenção Arendt, na possibilidade da identidade apesar das diferenças de perspectivas. "Esses interesses [públicos] constituem, na acepção mais literal da palavra, algo que inter-essa [inter-est], que se situa entre as pessoas e que, portanto, é capaz de relacionálas e mantê-las juntas" (Arendt, 2014, p. 226). 
No entendimento do público, aciona-se, ainda, o debate no âmbito da negociação argumentativa entre cidadãos. Habermas (2003a, 2003b) descreve publicidade, crítica e debate como os critérios que constituem a base da comunicação pública, que, por sua vez, vai produzir a opinião pública. Esteves (2011) analisa esses critérios e, a partir deles, faz suas considerações sobre três princípios da comunicação pública: (1) princípio do não fechamento do público (publicidade ou acessibilidade), que indica ampla liberdade de participação sob a ética do discurso, ou seja, que nenhuma exclusão seja admitida entre todos aqueles que possuem a competência da palavra e do agir; (2) Princípio de não fechamento temático da comunicação pública (discutibilidade), em que a própria seleção dos assuntos se torna tarefa da comunicação pública; por fim, (3) princípio da paridade argumentativa (racionalidade), que postula que a todos os participantes deve ser reconhecida uma igualdade essencial de estatuto, prevalecendo a força de validade dos argumentos apresentados.

Essa caracterização de comunicação pública marca sua dimensão eminentemente argumentativa. Trata-se, portanto, de princípios normativos da comunicação pública, seu modelo e preceito ético que, como chama atenção Esteves, será sempre tensionado pela facticidade: "o desafio que se coloca é, sim, o de construir um entendimento dessa mesma realidade, das diversas situações e dimensões sociais concretas que a constituem, que possa ir mais além do senso comum" (Esteves, 2011, p. 212).

Direcionando-se para o entendimento operacional das práticas que se dão a verificar, Weber (2007, 2009, 2011) aborda a comunicação pública na perspectiva política e privilegia a instauração do debate público em rede. A autora chama atenção de que a comunicação pública não se restringe às ações de comunicação dos governos: "a comunicação pú-blica existe quando se constitui como redes, a partir da circulação de temas de interesse público gerados em sistemas de comunicação" (Weber, 2007, p. 23). A autora defende que

a comunicação pública não pode ser determinada, ape-nas, a partir de legislação ou estruturas mas é configurada pela circulação de temas de interesse público, nos modos de debater e repercutir estes te $\neg$ mas, sem controle direto. Trata-se da comunicação pública constituída pela abordagem e circulação de temas vitais à sociedade, ao Estado e à política. (Weber, 2007, p. 24).

Veem-se aqui duas ideias centrais: uma relacionada ao conteúdo da comunicação pública (temas de interesse público) e outra, à sua forma (redes). 0 interesse público é caracterizado pelos princípios de funcionamento do espaço público. A ideia de rede ressalta que esses temas são lançados e reconhecidos por diferentes sistemas de comunicação ligados a instituições públicas e privadas, formando um emaranhado de fluxos de informações que perpassa os indivíduos.

Entende-se que cada rede tem sua própria complexidade no modo e no interesse específico de abordar temas de interesse público e a repercussão destes é proporcional aos interesses (públicos e privados) de outras redes. São, então, tecidos os debates no espaço público e desencadeados ataques, pactos e defe $\neg$ sas em torno de temas essenciais à sociedade a partir de perspectivas tão públi־cas quanto privadas (Weber, 2007, p. 25).

As redes de comunicação pública, então, são tomadas por temas sempre tensionados por interesses públicos e privados. Esse é o nível da facticidade, indicado por Esteves, em contraste com o nível normativo. A questão que se coloca é analisar essa realidade buscando ver o que potencializa e o que barra a realização da comunicação pública ideal, promotora de cidadania e qualificadora de um estado democrático.

Assim sendo, em resumo, a conceituação da comunicação pública aqui trabalhada passa pelo sistema político, entendendose a democracia como pressuposto. Considera-se que a comunicação pública estabelecedora do debate público é promovida pela circulação de temas de interesse na esfera pública, inclusive, midiática, incitada por manifestações sociais, pela sociedade organizada, por seus cidadãos e também pelo Estado. Dessa forma, faz-se referência à comunicação pública não 
apenas para identificar a fala da coisa pública ou governamental, mas, antes, do interesse público. Sua abordagem deve reconhecer os propósitos éticos, mas não pode se limitar pela perspectiva normativa, a ser permanentemente tensionada pela realidade fática, ou seja, as possibilidades concretas da comunicação pública.

\section{CARÁTER ESTRATÉGICO E COMUNICAÇÃO ORGANIZACIONAL}

Na defesa do interesse público, a comunicação pública assume caráter estratégico. Trata-se de promover a comunicação com vistas a alcançar objetivos selecionados estrategicamente em detrimento de outros. 0 objetivo pode relacionar-se à defesa argumentativa de um valor através de narrativas que possam confirmar a validade - do valor e da instituição que 0 representa. Considerando o tensionamento permanente entre interesses públicos e privados, esses objetivos estratégicos da instituição conjugarão também a visão para objetivos privados ou mais particulares.

Weber (2011) destaca que a comunicação realizada pelos atores públicos tem caráter estratégico pois, se responde às necessidades de transparência, é também marcada por interesses privados na busca por visibilidade política, uma imagem pública favorável, adesão de opiniões e, por fim, votos.

Para a compreensão dessa dimensão estratégica contribuem os estudos da comunicação organizacional, entendida "como processo de construção e disputa de sentidos no âmbito das relações organizacionais" (Baldissera, 2009, p.135). A partir desse entendimento, o conceito de comunicação estratégica é dado necessariamente em relação e não como simples intenção de influenciar traduzida numa equação de causa e efeito.

Reforçando que é em comunicação que os sujeitos se relacionam para construir uma organização, Baldissera (2014) aponta três âmbitos organizacionais: (1) organização comunicada, referindo-se aos processos formais, planejados, autorizados, pensados estrategicamente para sua visibilidade; (2) organização comunicante, que existe sempre que algum sujeito estabelece relação direta com a organização e, portanto, produz sentido - também abarca a comunicação comunicada; e (3) organização falada, que trata da comunicação que tem a organização como referência, mas os sujeitos não estão em relação direta com a organização, referindo-se a ela em ambientes externos. Nos termos de uma abordagem complexa assumida pelo autor, a comunicação de uma organização será diálogo, relação, estratégia e discurso autorizado, mas também resistência, cooperação e subversão.

Isso significa assumir uma visão sociológica da instituição de sentidos, fundamental para a abordagem da comunicação organizacional. A partir dessa perspectiva, Marques (2015, p. 7) destaca que

a comunicação é enfocada a partir de um contexto conformado pela relação entre os interlocutores: a organização é percebida como sujeito relacional complexo que, em interação com seus membros e com a sociedade, configura um dado contexto de interações. Assim, a abordagem comunicacional no contexto das organizações se interessa pela análise do movimento, pelo estudo de como a interação atualiza a relação da organização e seus interlocutores, posicionando-os e reposicionando-os frente aos outros para que sentidos sejam construídos e reconstruídos de forma incessante (Marques, 2015, p. 7).

Nesse mesmo sentido, Mumby (2009, p. 197) afirma que abordar as realidades organizacionais "é uma questão de entender como membros se envolvem coletivamente em processos de produção de sentido por meio de práticas de comunicação". 0 autor defende que as organizações e os processos organizacionais são políticos por definição, indicando a adoção de uma perspectiva crítica que explore as articulações entre comunicação, poder e organização. 
Deetz também ressalta que, menos que uma ferramenta de gestão, a comunicação deve ser abordada como processo fundamental para a existência das organizações. Assim, o foco "não [é] a transmissão, mas a formação do significado, da informação e do conhecimento, bem como o grau em que esse processo é livre e aberto em relação à inclusão das pessoas e do seu contexto" (Deetz, 2010, p. 85). É nesse sentido que o autor vai defender que um dos principais papéis da área da comunicação organizacional é desenvolver conceitos e práticas para uma democracia mais participativa, que permitam que a sociedade possa ganhar "mais produtivamente a partir de nossas diferenças" (Deetz, 2010, p. 97).

Pérez (2012), igualmente, defende o abandono de uma concepção funcionalista da comunicação como transmissão em nome de sua compreensão relacional, o que, consequentemente, significa uma outra abordagem para os sujeitos e suas organizações. Entender um sujeito não puramente racional, mas sim relacional, leva a perceber as organizações não como fechadas em si, mas como sistemas abertos. Não se trata de estruturas fixas, mas de sistemas complexos não mais abordados a partir de uma ordem mecânica.

Dessa forma, o fazer organizacional está necessariamente compreendido por uma comunicação dialógica e participativa, marcada pela negociação permanente. Assim, a estratégia não é mais abordada em termos de conflito (marco militar em que historicamente sua ideia foi desenvolvida), mas "a estratégia como ciência da articulação humana" (Pérez, 2012, p.182, tradução nossa). Esse é o centro da argumentação da "nueva teoría estratégica" (NTE) advogada por Pérez em parceria com outros autores da comunicação organizacional.

Na nova teoria estratégica o olhar relacional é o que marca a abordagem das organizações e das pessoas, o que implica alterar a compreensão "de fazer estratégias para viver estrategicamente" (Pérez, 2012, p.189, tradução nossa). Ou seja, a organização deixa se ser vista como a formuladora e controladora de estratégias (paradigma gerencial) para ser vista como espaço de interação e negociação de visões e realizações de mundo.

Isso significa entender a ação estratégica como ação comunicacional, como relação que não pode afastar o outro a decisão estratégica de eleição entre alternativas que projetam um futuro desejado mas sempre incerto implica, necessariamente, o cálculo do outro.

Estratégia é a disciplina que nos ajuda a eleger o conjunto de decisões supostamente melhores para alcançar os cenários de futuro que temos visado e que constituem nossas metas, sabendo que não estamos sozinhos e que há outras pessoas, organizações, forças ou sistemas que com sua intervenção podem favorecer ou dificultar o alcance dessas metas (Pérez, 2012, p. 51, tradução nossa).

Em resumo, Pérez (2012) apresenta a estratégia como um processo comunicacional de atuação de sujeitos no mundo que implica uma visão de futuro imaginada e desejada diante da qual se impõe a escolha de metas e ações, um caminho a ser traçado que deve ser anunciado e distribuído em tarefas. Lembrando que a estratégia não se realiza no desenho virtual desse caminho, mas sim no seu fazer, na sua construção - comunicacional - diante dos outros. A estratégia é um fazer direcionado a determinados interesses, mas sempre tensionado e refeito por outros interesses que serão colocados pelo premente convívio público e social.

\section{A INSTITUIÇÃO NAS PERSPECTIVAS NORMATIVA, FÁTICA E ESTRATÉGICA}

A abordagem dos processos de comunicação pública, conforme argumentado, deve destacar os preceitos éticonormativos marcados pela relevância pública e os aspectos da facticidade interacional dos sujeitos, atentando para a 
ação comunicacional que, afinal, concretiza aqueles ideais. Além dos aspectos normativos e éticos, há de se considerar as questões estratégicas relacionadas à comunicação pública e à disputa de poder e visibilidade decorrente do permanente embate entre interesses públicos e privados que caracteriza o espaço público. Temos, portanto, três âmbitos fundamentais à compreensão da comunicação pública - normativo, fático e estratégico-, que buscaremos aplicar à realidade institucional como proposta para a análise dos processos de comunicação pública instaurados a partir das instituições.

Partindo do entendimento mais amplo da instituição social como um todo - conforme abordagem de Castoriadis (1982), Berger e Luckmann (1998) e Braga (2010) -, é possível tomar a instituição formalizada, atentando para seu processo instituinte, portanto comunicacional. Ao colocar em comunicação os atores e ao se comunicar, a instituição ativa o próprio processo de institucionalização e viabiliza as interações sociais em seu âmbito.

Assim sendo, para pensar uma instituição é necessário pensar nos sentidos que a constituem, criam identificação e permitem seu reconhecimento. Dessa forma, veem-se as interações comunicativas como viabilizadoras dos sentidos comuns, ou seja, como processo instituinte da instituição, tanto internamente (na interação com seus sujeitos), como externamente (na interação com outras instituições e outros sujeitos sociais). Ou seja, para dentro ou para fora, a instituição se afirma e se reafirma, conquista espaço e reconhecimento, comunicando-se. Porque a instituição não pode se instituir por outro processo que não seja o da interação comunicacional.

Nesse contexto, para as instituições, comunicar é uma questão de existência: é estratégia instituinte. 0 ato de comunicar é (re)criador por natureza da instituição e essa (re)criação só pode acontecer na interação comunicativa dos sujeitos. Por isso, a comunicação é assumida como estratégia instituinte da instituição. Isso quer dizer, antes de tudo, reconhecer a comunicação como fundante para uma instituição, configurada formalmente como uma organização pública ou privada. Portanto, a comunicação é entendida como condição primeva das instituições.

Tomar a comunicação como condição primeva e fundante de uma instituição significa que a sua abordagem enquanto fenômeno será, necessariamente, comunicacional. Portanto, a abordagem comunicacional da instituição deve ser feita sem reduzi-la apenas aos aspectos funcionais, mas conciliando os processos simbólicos do instituir social. A visada à instituição aqui proposta está direcionada às suas ocorrências mais formalizadas ou oficializadas, como é o caso de uma instituição pública ou de organizações privadas e sociais não-governamentais.

Ou seja, assume-se que, em um nível mais formalizado e oficializado (e apenas aí), as instituições equivalem às organizações - fazendo o destaque necessário de que nem toda organização pode ser tomada como instituição, embora toda organização possa, idealmente, acionar processos de institucionalização. Por isso, o campo de conhecimento da comunicação organizacional oferece suporte conceitual para a abordagem dos processos comunicacionais que se desenvolvem nos âmbitos institucionais mais formalizados.

A abordagem da instituição aqui apresentada está orientada pela comunicação pública e estrutura-se em três perspectivas: normativa, fática e estratégica. Cada uma delas indica uma forma privilegiada de olhar, um foco assumido que não exclui as demais perspectivas. Ao contrário, pretende possibilitar a integração das três como tentativa de compreender a dinâmica institucional como um todo. Assim, alinha-se ao paradigma indiciário que busca "fazer proposições de ordem geral a partir dos dados singulares obtidos" (Braga, 2008, p. 2008) e, portanto, não é simples descrição. Sua base, afirma 0 autor, não é colher e descrever, mas sim selecionar e organizar indícios para então fazer inferências. 0 objetivo é evitar a redução de elementos contextuais relevantes para a percepção do fenômeno comunicacional em foco. 


\section{Perspectiva normativa}

A perspectiva normativa diz respeito às normas que orientam a criação e o funcionamento da instituição, ao papel em defesa dos interesses públicos que se espera que desempenhe, independentemente de sua natureza pública ou privada. Portanto, fala-se do que é normativamente atribuído à instituição, das expectativas ideais e das potencialidades éticas de sua atuação.

Como defende Esteves (2011) ao falar do espaço público, a análise dessa perspectiva é um exercício crítico conduzido em nome de princípios ético-morais e que têm caráter essencialmente autorreflexivo: "neste plano ideal, os princípios ético-morais ditam ainda a sua lei enquanto referências orientadoras para uma transformação possível (desejável) das estruturas concretas" (Esteves, 2011, p. 185).

Aqui, as seguintes perguntas devem ser respondidas: quais ideais públicos orientam a instituição? Em que medida a definição institucional é pautada por e reforça interesses públicos? Uma possibilidade para chegar a essas respostas está na análise da legislação que rege o funcionamento da instituição e dos seus posicionamentos oficias, indicados por exemplo em seus estatutos e na sua definição de missão, visão e valores. Nessa perspectiva, assume-se, portanto, referência à dimensão normativa e ético-moral da comunicação pública e diante da qual coloca-se a realidade empírica - que está indicada nas duas perspectivas seguintes.

\section{Perspectiva fática}

A perspectiva fática destaca que a instituição está permanentemente em construção. Embora ela tenha um caráter objetivo e funcional, não é previamente dada, é uma contínua produção humana que se dá por meio da interação comunicativa - 0 que exige olhar para o nível intermediário da instituição, perto da ação dos sujeitos, como destaca Braga (2010). Nesse sentido, há, ainda, paralelo com a organização comunicante de Baldissera (2014).

Ao analisar a facticidade de uma instituição, importa compreender: como ela possibilita que os sujeitos se coloquem em relação? Como se dá a dinâmica relacional e a geração de sentidos proporcionada em seu espaço institucional? A resposta a essas indagações exige perceber as situações de interação vividas pelos sujeitos.

Destaca-se, portanto, essa perspectiva como a do acontecimento institucional, onde se assiste à atividade instituinte de sentidos e objetivos, aos atores construindo e desempenhando papéis e recriando seu lugar social e também o da instituição. Dessa forma, essa categoria marca diferenciação em relação aos sentidos já sancionados representados pela abordagem normativa.

\section{Perspectiva estratégica}

A perspectiva estratégica é aquela em que a instituição se apresenta como capaz de realizar as funções que a ela são conferidas e pode assim ser reconhecida. Relaciona-se à exigência da legitimação apontada por Berger e Luckmann (1998), que oferece explicações e justificações à ordem institucional dando status normativo a seus imperativos práticos e está necessariamente associada à linguagem.

Nessa perspectiva busca-se responder a: como se dá a comunicação estratégica da instituição? Que tipo de adesão e valores ela busca ao promover a comunicação por visibilidade e reconhecimento? Portanto, atenta-se para a produção 
profissional de comunicação da instituição com vistas à projeção de uma imagem que possa ser percebida positivamente a partir da proposição de sentidos estrategicamente reforçados. Aqui, faz-se referência à organização comunicada referida por Baldissera (2014) e ao caráter estratégico da comunicação pública destacado por Weber (2007, 2009, 2011).

Ressalta-se, ainda, conforme Pérez (2012), que essa estratégia não pode ser construída à parte da facticidade institucional, pois é abordada como um processo comunicacional de atuação de sujeitos no mundo que implica uma visão de futuro imaginada e desejada. Assim, a atuação estratégica será sempre interacional e implicará o cálculo permanente do outro.

\section{CONSIDERAÇÕES FINAIS}

As três perspectivas evidenciam que, diante de uma abordagem normativa do potencial ético da comunicação pública, há uma atuação institucional prática que é também estratégica e que se legitima justamente através da defesa do interesse público. Na pesquisa de mestrado que realizamos, essas três perspectivas foram apropriadas para a abordagem de uma instituição pública, a Defensoria Pública do Rio Grande do Sul. Mas acredita-se que essa tríade possa ser igualmente aplicada para outros tipos de instituições, sejam elas privadas ou comunitárias.

Os diferentes tipos de instituições implicariam uma expectativa de prevalência em relação às três dimensões. Na instituição pública, a princípio, espera-se o destaque para a perspectiva normativa; na empresa privada haveria a primazia da perspectiva estratégica orientada ao propósito do lucro; e na instituição do terceiro setor, como uma organização nãogovernamental, estaria ressaltada a perspectiva fática. Mas essa é apenas uma demarcação incipiente, relacionada à marca primeira da natureza da instituição.

Afinal, seu processo de institucionalização só será completo à medida que conjugue as três dimensões: sendo orientada por uma razão de ser validada, construindo e concretizando seus objetivos nas ações de seus atores e legitimando-se como tal. A ausência de quaisquer das perspectivas possivelmente resultará em um processo de institucionalização frágil, em que as referências de sentido institucional não são compartilhadas e legitimadas publicamente, ou seja, não são associadas a valores.

Ao apresentar a genealogia afirmativa de valores, Joas (2012) defende a triangulação necessária entre valores, instituições e práticas. "Os valores não devem permanecer simples valores. Eles só viverão se forem defendidos argumentativamente enquanto valores, mas sobretudo se forem sustentados por instituições e corporificados por práticas" (Joas, 2012, p. 200). As instituições apropriam os ideais em condições específicas, permitindo que o apelo ideal não apenas seja ouvido, mas realizado. A motivação a partir do valor é fundamental: "Quando o 'espírito' tiver se esvaído das instituições, não há mais confiança nelas" (Joas, 2012, p. 201).

Dessa forma, norma, facticidade e estratégia se integram numa complementaridade necessária para um processo vigoroso de institucionalização associado à uma comunicação pública plena. Uma instituição será legitimada, terá sua validade reconhecida, à medida que tiver uma defesa argumentativa (perspectiva normativa), apresentar suas narrativas (perspectiva estratégica) e as encarnar em suas práticas concretas (perspectiva fática). 


\section{REFERÊNCIAS}

ARENDT, H. A condição humana. 12. ed. - rev. Rio de Janeiro: Forense Universitária, 2014.

BALDISSERA, Rudimar. A teoria da complexidade e novas perspectivas para os estudos de comunicação organizacional. In: KUNSCH, Margarida M. Krohling (Org.). Comunicação organizacional. Vol. 1. Histórico, fundamentos e processos. São Paulo: Saraiva, 2009. p. 135-164.

Comunicação, cultura e interação nas organizações. In: MARCHIORI, Marlene. (Org.). Cultura e interação. São Caetano do Sul, SP: Difusão, 2014. p. 87-99.

BERGER, Peter L.; LUCKMANN, Thomas. A construção social da realidade: tratado de sociologia do conhecimento. 15. ed. Petrópolis, RJ: Vozes, 1998.

BRAGA, José Luiz. Comunicação, disciplina indiciária., Matrizes, São Paulo, n. 2, abril p. 73-88, 2008.

. Comunicação é aquilo que transforma linguagens. Revista Alceu, Rio de Janeiro, v. 10, n.20, p. 41-54, jan./jun. 2010.

CARNIELLI, Fiorenza Zandonade. A cidadania e a sua instituição: estudo de comunicação pública sobre a Defensoria do Rio Grande do Sul. Dissertação (Mestrado em Comunicação e Informação) - Programa de Pós-Graduação em Comunicação e Informação, UFRGS, 2016.

CASTORIADIS, Cornélius. A instituição imaginária da sociedade. Rio de Janeiro: Paz e Terra, 1982.

DEETZ, Stanley. Comunicação organizacional: fundamentos e desafios. In: MARCHIORI, Marlene (Org.). Comunicação e organização: reflexões, processos e práticas. São Caetano do Sul, SP: Difusão, 2010.

ESTEVES, João Pissarra. Sociologia da comunicação. Lisboa: Fundação Calouste Gulbenkian, 2011.

FRANÇA, Vera. Jornalismo e vida social: a história amena de um jornal mineiro. Belo Horizonte: UFMG, 1998.

FRANÇA, Vera; CORRÊA, Laura Guimarães. Mídia, instituições e valores. Belo Horizonte: Autêntica, 2012.

JOAS, Hans. A sacralidade da pessoa humana: nova genealogia dos direitos humanos. São Paulo: Editora Unesp, 2012.

HABERMAS, Jürgen. Mudança estrutural da esfera pública. Rio de Janeiro: Tempo Brasileiro, 2003a.

. Direito e democracia. Rio de Janeiro: Tempo Brasileiro, 2003b.

MARQUES, Ângela. Prefácio. In: OLIVEIRA, Ivone de Lourdes; PENNINI, Anice; MOURÃO, Isaura. Compreendendo um campo de conhecimento: reflexões epistemológicas sobre a Comunicação Organizacional a partir de autores brasileiros. Curitiba: CVR, 2015.

MUMBY, Dennis. A comunicação organizacional em uma perspectiva crítica. Organicom - Revista Brasileira de Comunicação Organizacional e Relações Públicas, n.10/11, p. 191-207, 2009. 
PÉREZ, Rafael A. Pensar la estrategia: otra perspectiva. Buenos Aires: La Crujía, 2012.

WEBER, Maria Helena. Na comunicação pública, a captura do voto. Logos 27: Mídia e Democracia, Rio de Janeiro: a. 14, p. 21-42, 2. sem. 2007.

Comunicação organizacional, a síntese. Relações públicas, a gestão estratégica. Organicom - Revista Brasileira de Comunicação Organizacional e Relações Públicas, n. 10/11, p. 70-75, 2009.

Estratégias da comunicação de estado e a disputa por visibilidade e opinião. In: KUNSCH, Margarida M. Krohling (Org.). Comunicação pública, sociedade e cidadania. São Caetano do Sul, SP: Difusão, 2011.

Texto recebido em 29.03.2017 e aprovado em 30.06.2017. 